\title{
ESTUDO DO COMPORTAMENTO DO GADO HOLANDÊS EM SISTEMA DE SEMI-CONFINAMENTO
}

\author{
Behavior Survey of Holstein Cattle In a Free-Stall
}

\author{
Sylvio Antonio Ribeiro Degasperi ${ }^{1}$ \\ Carlos Henrique Coimbra ${ }^{2}$ \\ Cláudia Turra Pimpão, Felipe Pohl de Souza, Kung Darh Chi, Percy Glaser Junior, Renata Ernlund \\ Freitas de Macedo ${ }^{3}$ \\ Paulo Roberto Barreto Piekarski, Rodrigo de Almeida ${ }^{4}$ \\ André Barbosa, Wanderley Margotti Karan, André T. Pereira, Angela Regina Huber, Airton José \\ Marenda Ferreira, Caetano João Morestto, Diva Scholz, Edmundo Alberto Mercer, Eliane Manzini, \\ Fabiola Weinhart Jazar, Gabrielle Zoccoli, Izabela Toledo, Mônica de Paula, Percy Janzen, Rene \\ de Napoli, Siegardt Kleig, Ticiana Strauss da Costa 5
}

\section{Resumo}

Foram avaliados os dados relativos à observação de atividades comportamentais das vacas leiteiras da raça Holandesa da Fazenda Experimental Gralha Azul da Pontifícia Universidade Católica do Paraná, localizada no Município de Fazenda Rio Grande, Paraná. Durante um período de 15 dias manteve-se o registro de 24 horas de cada atividade de cada animal deitado, em pé, ruminando, andando, defecando, urinando, bebendo água, lambendo e comendo, cujas médias, desvio padrão e coeficiente de variação foram de: 4,97 $\pm 0,33$; $6,63 \%, 4,35 \pm 0,15 ; 3,44 \%, 3,69 \pm 0,12 ; 3,25 \%, 98 \pm 0,12 ; 6,06 \%, 4,32 \pm 0,20 ; 4,62 \%, 4,67 \pm 0,23 ; 4,92 \%, 2,75$ $\pm 0,21 ; 7,63 \%, 2,22 \pm 0,24 ; 10,81 \%$ e $2,93 \pm 0,18 ; 6,14 \%$, respectivamente. Os períodos de tempo significativos $(\mathrm{p}<0,01)$ sobre todas as atividades foram os de 0 a 2 horas e 3 a 5 horas da manhã.

Palavras-chaves: Comportamento, Vacas, Holandesa

\section{Abstract}

Data related to the behavior Holstein dairy cows at Fazenda Experimental Gralha Azul of Pontifícia Universidade Católica do Parana, located in the city of Fazenda Rio Grande county, state of Parana were analyzed. For 15 days, records of each behavior activity were kept around the clock. Average, standard deviation and CV (\%) of the activities such as lying, standing, rumination, walking, defecation, urination, drinking, grooming and eating were: $4,97 \pm 0,33 ; 6,63 \%, 4,35 \pm 0,15 ; 3,44 \%, 3,69 \pm 0,12 ; 3,25 \%, 98 \pm 0,12$; $6,06 \%, 4,32 \pm 0,20 ; 4,62 \%, 4,67 \pm 0,23 ; 4,92 \%, 2,75 \pm 0,21 ; 7,63 \%, 2,22 \pm 0,24 ; 10,81 \%$ and $2,93 \pm 0,18 ; 6,14 \%$, respectively. The time periods from 0 to $2 \mathrm{a} . \mathrm{m}$. and from 3 to $5 \mathrm{a}$.m. were significant $(\mathrm{p}<0,01)$ over all the activities.

Key-words: Behavior, Cows, Holstein.

\footnotetext{
Livre Docente, Ex-Diretor do Curso de Zootecnia, CCAA, São José dos Pinhais, PUCPR. Engenheiro Agrônomo, Professor Mestre, CCAA, São José dos Pinhais, PUCPR Médicos Veterinários, Professores Mestre, CCAA, São José dos Pinhais, PUCPR Médicos Veterinários, Professores Mestre, Consultores do Departamento de Zootecnia, UFPR.

Acadêmicos do CCAA, São José dos Pinhais, PUCPR
} 


\section{Introdução}

Parte significativa da vida de um bovino, sendo herbívoro, é consumida nos atos de ingestão e ruminação (55\% a 60\%). Os períodos de ingestão aumentam na medida que há um decréscimo na qualidade da pastagem. Um padrão diurno de ingestão coincide com o padrão de seus congêneres selvagens, ou seja, pico de consumo ocorrendo ao amanhecer e no entardecer. Este padrão tende a ser mantido mesmo quando os animais estão confinados. Bovinos, caso tenham escolha, preferem estar ao ar livre no verão e confinados no inverno.

Em climas quentes, as altas temperaturas durante o verão causam impacto no consumo e no comportamento de ingestão de água. Bovinos procuram sombra, bebedouros, poças e cursos d'água para se refrescarem e ser livrarem de insetos. Há um acréscimo significativo no consumo de água como o aumento na produção de leite, sendo que a água é o componente mais barato de qualquer dieta para gado leiteiro, mas, se restrito, pode ser o componente de maior impacto na diminuição dos lucro com a venda do leite.

Os bovinos mostram alguma agilidade em movimentar-se. Em seu ambiente natural, os bovinos caminham longas distâncias em busca de forragens e água. A prática de confinamento restringe muitos de seus movimentos típicos, contribuindo para a manifestação de vários comportamentos atípicos, próprios de animais entediados. A laminite, enfermidade presente em várias etiologias, é um dos problemas mais sérios de bem-estar animal, associado com o manejo intensivo de bovinos.
$\mathrm{O}$ ato de coçar-se ou lamber-se (grooming), por si mesma ou por companheiras de rebanho, são elementos essenciais na manutenção do corpo e são importantes na estrutura social do rebanho. A ligação entre a mãe e o bezerro recém-nascido é estabelecida na medida que a vaca lambe seu bezerro logo após o parto.

Praticamente metade das horas que um bovino adulto encontra-se acordado é gasta descansando, normalmente deitados em decúbito ventral, com os pés e pernas embaixo do corpo. A qualidade da cama oferecida aos animais em confinamento determina a freqüência e a duração dos períodos de descanso. O enchimento do rúmen e a prenhez influenciam o lado com que a vaca deita. Vacas secas e novilhas prenhas que deitam após comerem, tendem a deitar no seu lado esquerdo enquanto descansam e mantém sua garupa voltada para cima, quando em área inclinada.

Os bovinos urinam com menor freqüência, mas com esforço maior do que defecam. Têm pouco controle sobre o processo de eliminação e este tende a ocorrer por acaso. A excitação (quando introduzidos em novo ambiente), presença de estranhos, abusos e maus tratos, ou qualquer efeito traumatizante, geralmente resulta em imediata eliminação de urina e/ou fezes. O fornecimento de cama limpa e com adequada capacidade de absorção, trocada a intervalos regulares, é uma necessidade para bovinos em manejo intensivo.

Hancock, (1950, 1954) apresenta padrões de comportamento para gêmeos bovinos monozigóticos em pastejo, conforme esta sumarizado na Tabela 1.

TABELA 1 - Padrões de comportamento para gêmeos bovinos em pastejo

TABLE 1 - Standards of behavior for bovine twin on the feed

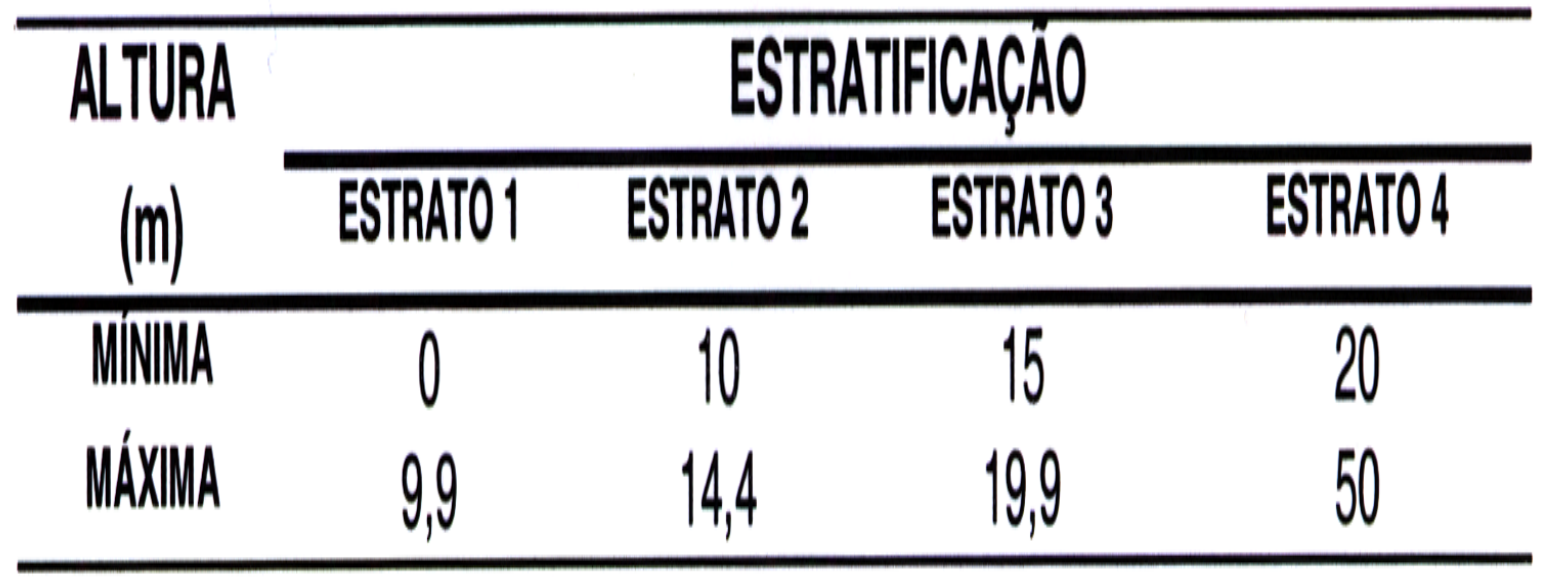




\section{Objetivo}

O objetivo do presente estudo foi avaliar o comportamento de vacas da raça Holandesa em condições de semi-confinamento durante o inverno com pouca oferta de pastagens em uma propriedade da Região Metropolitana de Curitiba.

\section{Material e método}

Este trabalho foi realizado na Fazenda Experimental Gralha Azul - Pontifícia Universidade Católica do Paraná, localizada no Município de Fazenda Rio Grande na Região Centro-leste do Estado do Paraná, que apresenta o clima $C f b$, segundo Köppen. Durante o período em que foram desenvolvidas as atividades registrou-se uma amplitude de $10,0^{\circ} \mathrm{C}$ a $21,3^{\circ} \mathrm{C}$ com a temperatura média de $15,5^{\circ} \mathrm{C}$, umidade relativa do ar de $93 \%$ a $100 \%$ e um índice pluviométrico médio de $120 \mathrm{~mm} / \mathrm{m}^{2}$.

No presente trabalho foram utilizadas 12 Holandesas preto e branco, divididas nas seguintes categorias: vacas em lactação, vacas secas e novilhas prenhes. Os animais foram previamente identificados com números, marcados em seus flancos e garupa, utilizando-se tinta óleo amarela e rolo de pintura. Os números dos flancos apresentavam dimensões aproximadas de $40 \mathrm{~cm}$ e os da garupa $20 \mathrm{~cm}$. Todos os animais foram previamente pesados em balança eletrônica e everminados com levamizole tendo sido conduzidos para a área de observação, com aproximadamente 2,5 ha de pastagem nativa, contígua ao estábulo de ordenha. Os animais tinham acesso ad libitum à água, sal mineral, silagem de milho e feno pré-secado de azevém. As vacas em lactação eram ordenhadas duas vezes ao dia, ocasião em que recebiam 4 kg de ração comercial com 16\% de proteína. Os animais foram observados durante 15 dias, compreendidos entre 5 e 19 de julho de 1999, durante as 24 horas do dia por oito observadores, divididos em equipes de 3 , que revezavam-se em turnos de 3 horas. A cada 3 períodos os membros das equipes eram alternados. Para facilitar as observações, os períodos de 3 horas eram divididos em "sub-períodos" de 15 minutos, nos quais eram apontadas as atitudes de cada animal, utilizando-se os seguintes códigos:

D Deitado

Ep Em pé

$\mathrm{R}$ Ruminando

A Andando

F Defecando

U Urinando

B Bebendo

L Lambendo

C Comendo no cocho

Os resultados foram avaliados por freqüência absoluta dos eventos, e para análise estatística dos dados foi utilizado o delineamento em blocos casualizados, sendo que foram considerados oito tratamentos com períodos de três horas de observações cada, com nove blocos relativos às atitudes. O teste de Tukey foi utilizado para analisar as médias dos períodos de tempo.

\section{Resultados e discussão}

As médias e os seus respectivos padrões de cada parâmetro observado são apresentados na Tabela 2.

TABELA 2. Médias estimadas, desvios padrões e respectivos coeficientes de variação dos parâmetros observados por vaca e por dia.

TABLE 2. Estimated averages, standard deviations and respective coefficients of variation of daily observed parameters per cow per day.

\begin{tabular}{lc}
\hline Parâmetros observados & $\overline{\mathbf{X}} \pm \mathbf{S} ; \mathbf{C V}$ \\
\hline Deitado (D) & $4,97 \pm 0,33 ; 6,63 \%$ \\
Ruminando (R) & $3,69 \pm 0,12 ; 3,25 \%$ \\
Em pé (Ep) & $4,35 \pm 0,15 ; 3,44 \%$ \\
Andando (A) & $1,98 \pm 0,12 ; 6,06 \%$ \\
Bebendo (B) & $2,75 \pm 0,21 ; 7,63 \%$ \\
Comendo no cocho (C) & $2,93 \pm 0,18 ; 6,14 \%$ \\
Defecando (F) & $4,32 \pm 0,20 ; 4,62 \%$ \\
Urinando (U) & $4,67 \pm 0,23 ; 4,92 \%$ \\
Lambendo (L) & $2,22 \pm 0,24 ; 10,81 \%$ \\
\end{tabular}


TABELA 3. Resumo da análise de variância segundo períodos de tempo.

TABLE 3. Summary of the analysis of variance according to periods of time.

\begin{tabular}{|c|c|c|c|c|c|c|}
\hline & \multirow{2}{*}{\multicolumn{2}{|c|}{ Murcote $* * *$}} & \multirow{2}{*}{\multicolumn{2}{|c|}{ Ponkan }} & \multirow{3}{*}{$\begin{array}{c}\text { Outras } \\
\text { cultivares } \\
\text { *** }\end{array}$} & \multirow{3}{*}{$\begin{array}{c}\text { Cultivares não } \\
\text { identificadas } \\
* *\end{array}$} \\
\hline & & & & & & \\
\hline Fevereiro & 2,10 & $\mathbf{a}$ & $* \approx$ & & & \\
\hline Março & 1,91 & $\mathbf{a b}$ & 1,18 & $\mathbf{a}$ & 0,83 & 2,66 \\
\hline Abril & 1,83 & $a b c$ & 1,05 & $\mathbf{a}$ & 0,76 & 3,04 \\
\hline Maio & 1,67 & $a b c$ & 0,28 & b & 0,65 & 0,71 \\
\hline Junho & 1,60 & $a b c$ & 0,23 & b & 0,41 & 0,76 \\
\hline Julho & 0,46 & c & 0,28 & b & 0,69 & 0,96 \\
\hline Agosto & 0,54 & $c$ & 0,32 & b & 0,92 & 0,47 \\
\hline Setembro & 0,55 & $c$ & $* *$ & & 0,83 & 0,86 \\
\hline Outubro & 0,57 & $c$ & $* *$ & & 0,93 & 0,85 \\
\hline Novembro & 0,85 & bc & $* *$ & & $* *$ & $* *$ \\
\hline Dezembro & 0,94 & be & $* *$ & & $* *$ & $* \approx$ \\
\hline Janeiro & $* *$ & & $* *$ & & $* \approx$ & $* \approx$ \\
\hline Média anual & 1,19 & & 0,56 & & 0,75 & 1,29 \\
\hline
\end{tabular}

* Precos corrigidos pelo INPC-IBG

A experimentação foi altamente significativa para os períodos de tempo e com o teste de médias (teste de Tukey), observou-se diferença significativa dos seguintes períodos de tempo: 0-2 e 3-5 horas em relação aos demais períodos (6-8; 9-11; 12-14; 15-17; 18-20; 21-23), denotando uma alta ocorrência dos parâmetros deitado (D) e ruminando (R) e baixa ocorrência dos demais parâmetros nos mesmos períodos de tempo.

\section{Padrões de comportamento}

\section{Em descanso}

O descanso do indivíduo é vital para sua integração e mediação com o meio ambiente. Apesar das vacas poderem dormir em pé, o fato de deitarem contribui para a sua facilitação social bem como nas suas funções fisiológicas. As vacas deitam-se em decúbito ventral ou lateral, posição esta que os animais podem permanecer por longos períodos durante o dia. A duração do tempo em que permanecem deitadas depende do tipo de instalação, do conforto que a cama ou a área oferece, do tipo de dieta, período de gestação e fatores climáticos. Em relação à luminosidade e à temperatura, as vacas permanecem mais tempo deitadas à noite (80\%) do que de dia (58\%). Existe uma forte relação entre o animal deitado e a ruminação. Em torno de 80\% da ruminação ocorre com o animal deitado ou em descanso. Embora ainda pouco conhecidos, alguns aspectos da ruminação levam o animal a um estado de sonolência, cuja função restauradora dos mecanismos fisiológicos somente é alcançada pelo sono profundo. A ruminação é um ato reflexo resultante de estímulos mecânicos que está diretamente relacionado com o tipo e a quantidade da dieta. Quanto melhor o alimento é ruminado, melhor será digerido e eliminado, dando espaço para mais alimentos. Assim, a ruminação determina a quantidade de a ingestão futura.

No presente trabalho, as vacas deitavam-se em torno de cinco vezes $(4,97 \pm 0,33)$ ao longo de 24 horas, com a ruminação $(3,69 \pm$ 0,12 vezes/24h) acompanhando estes os períodos de repouso. Verificou-se esta associação,

FIGURA 1 - Animais deitados e ruminando ao longo de 24 horas.

FIGURE 1 - Lying and ruminating animals throughout 24 hours.

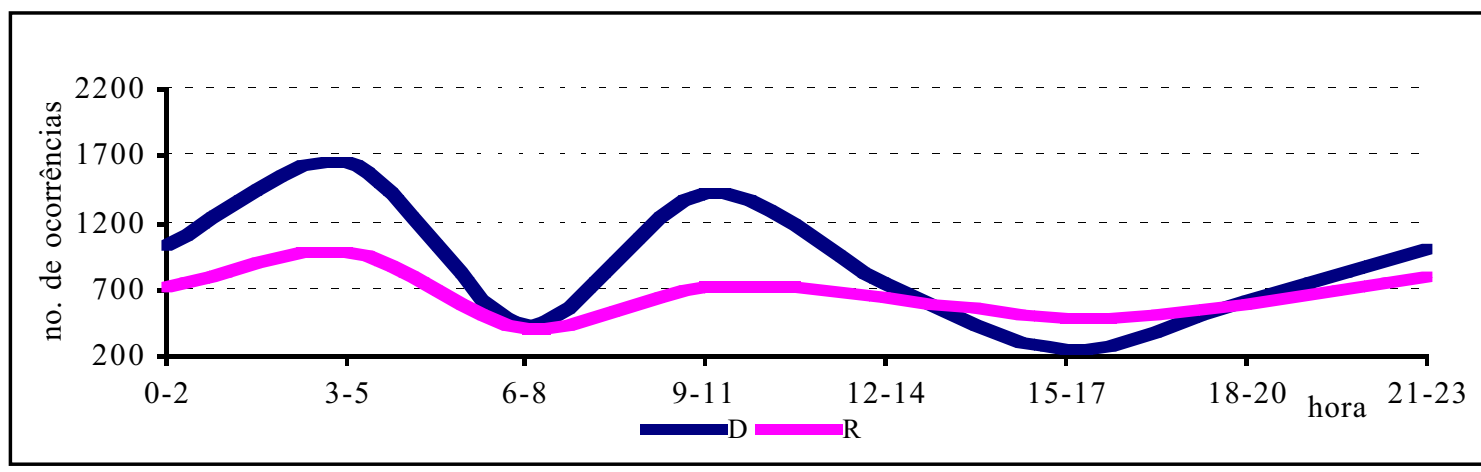

Nota: $(\mathrm{D}=$ Deitado; $\mathrm{R}=$ Ruminando $)$ 
de forma significativa $(\mathrm{p}<0,01)$, no período compreendido entre meia-noite e cinco horas da manhã (Fig. 1).

\section{Em pé}

Os bovinos têm uma motivação inata para a locomoção. Estando em pé, os sentidos do olfato e da visão são facilitados na busca de alimentos e de fontes de água. A movimentação é a principal resultante desta busca. A luminosidade permite melhor visualização na seleção do alimento, e a dessedentação feita após a ingestão de alimentos e também tem a função de controlar a temperatura corpórea. Assim, este conjunto de atividades, também com finalidade social, é, geralmente, feito ao amanhecer e ao entardecer, sendo os bovinos animais crepusculares. Sendo animais gregários, os bovinos, quando em pastejo, não competem entre si. Quando o alimento é fornecido no cocho a dominância previamente estabelecida no grupo torna-se evidente pela competição alimentar.

As observações neste trabalho corroboram com este padrão de comportamento. As atividades em pé $(4,35 \pm 0,15)$ como andar, comer e beber água $(1,98 \pm 0,12 ; 2,93 \pm 0,18$ e 2,75 $\pm 0,21$,

FIGURA 2 - Animais em pé, andando, bebendo e comendo ao longo de 24 horas.

\section{FIGURE 2 - Standing, in foot, walking, drinking and eating animals throughout 24 hours.}

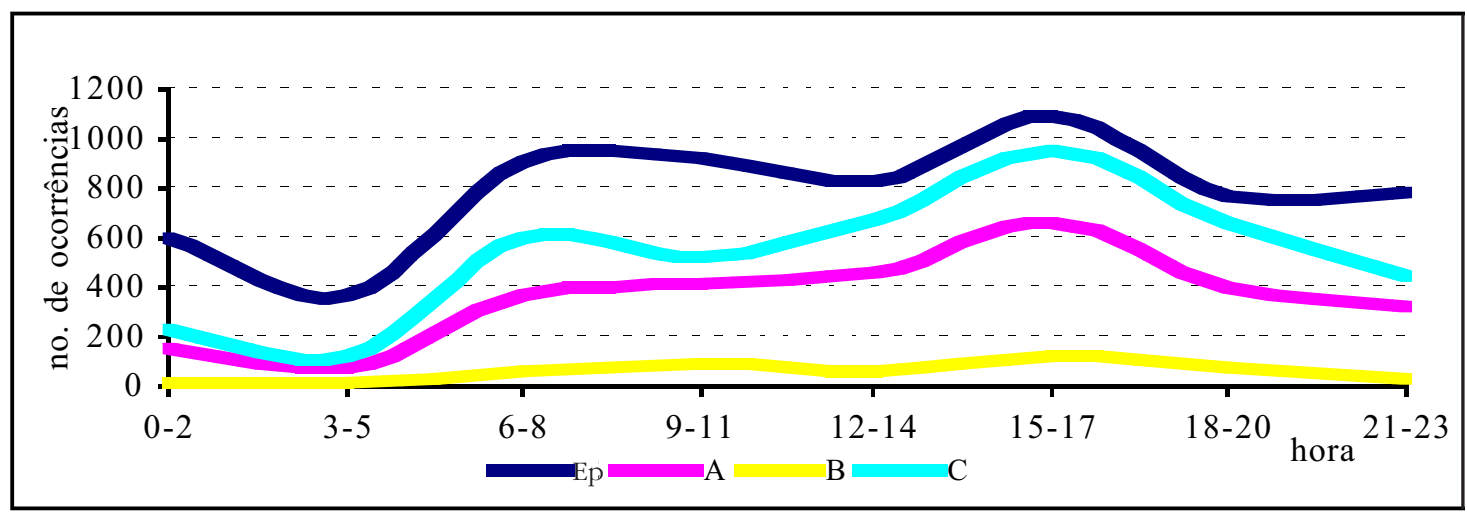

Nota: $(\mathrm{Ep}=$ em pé; $\mathrm{S}=$ andando; $\mathrm{B}=$ bebendo; $\mathrm{C}=$ comendo $)$

\section{Eliminação}

A eliminação das fezes e urina corresponde em média de $40 \mathrm{~kg}$ e $30 \mathrm{~kg}$, respectivamente, por $500 \mathrm{~kg}$ de peso vivo. A freqüência desta eliminação varia conforme a dieta, temperatura/umidade relativa do ar e a densidade populacional de um grupo. Vacas alimentadas no cocho defecam com menor freqüência $\left(4 \mathrm{dia}^{-1}\right)$ se comparadas com aquelas em pasto $\left(9 \mathrm{dia}^{-1}\right)$. A umidade relativa do ar, quando alta, também aumenta a freqüência de defecação, e a densidade populacional alta reduz esta freqüência. A eliminação da urina é, assim como a defecação, um ato involuntário nos bovinos, e da mesma forma também é determinado, principalmente, pelo tipo de dieta. A freqüência de micção pode variar de quatro a 10 vezes por dia. A defecação e a micção podem ser feitas tanto com a vaca deitada quanto em pé, mas geralmente a defecção é feita com o animal em movimento e a micção com o animal em pé.

Analisando os dados registrados neste trabalho, pôde-se verificar que tanto as médias de defecação $(4,32 \pm 0,20)$ quanto as de micção $(4,67 \pm 0,23)$ estão dentro da freqüência normal fisiológica, considerando a dieta, principalmente, a densidade populacional e a umidade relativa, ocorrendo com maior freqüência quando os animais estavam em pé e/ou andando (Fig. 3). 
FIGURA 3 - Animais defecando e urinando ao longo de 24 horas.

FIGURE 3 - Defecating and urinating animals throughout 24 bours.

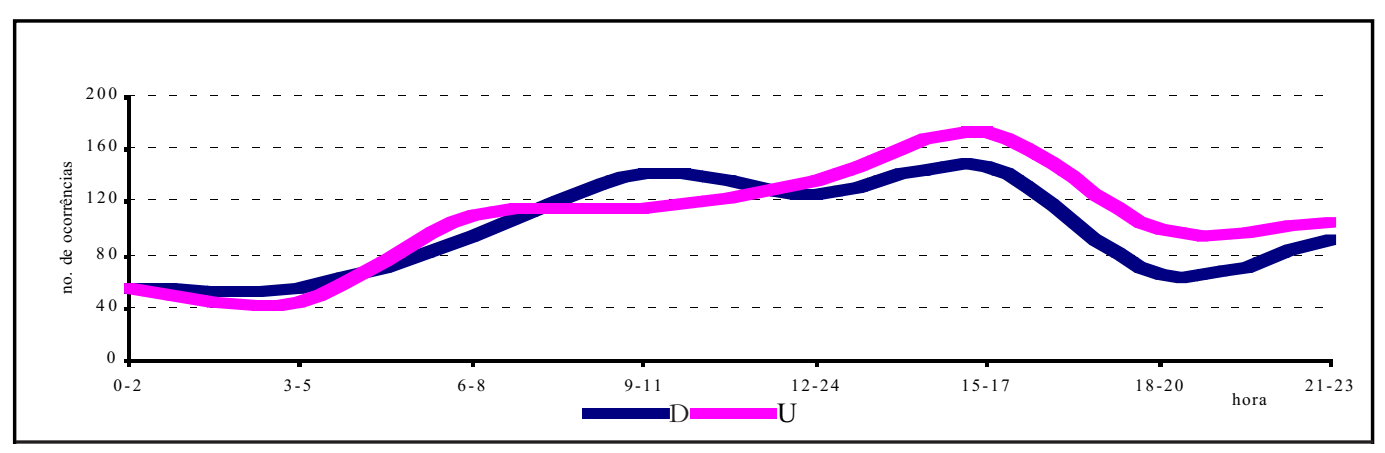

Nota: $(\mathrm{D}=$ defecando; $\mathrm{U}=$ urinando $)$

respectivamente) tiveram maior ocorrência nos períodos de seis a oito horas da manhã e das três a cinco horas da tarde, correspondendo o amanhecer e anoitecer durante o inverno (Fig. 2).

\section{Limpeza (grooming)}

O cuidado com a própria pelagem é, acima de tudo, um bom indicador de saúde nos animais. $\mathrm{O}$ ato de lamber-se e lamber as companheiras é um comportamento herdado dos ancestrais selvagens, que além de limpeza tinha a finalidade de extrair sal da pelagem. Os bovinos domésticos mantém este comportamento, que além da higiene individual, tem um papel importante na interação social do grupo, reforçando os laços entre os indivíduos, independente da hierarquia.

Outro aspecto fisiológico resultante do ato de lamber umas as outras é a redução da freqüência cardíaca, denotando um efeito calmante e relaxante. Este fato leva a crer que o ato de lamber

FIGURA 4 - Animais lambendo-se ao longo de 24 horas.

FIGURE 4 - Animals licking themselves throughout 24 hours.

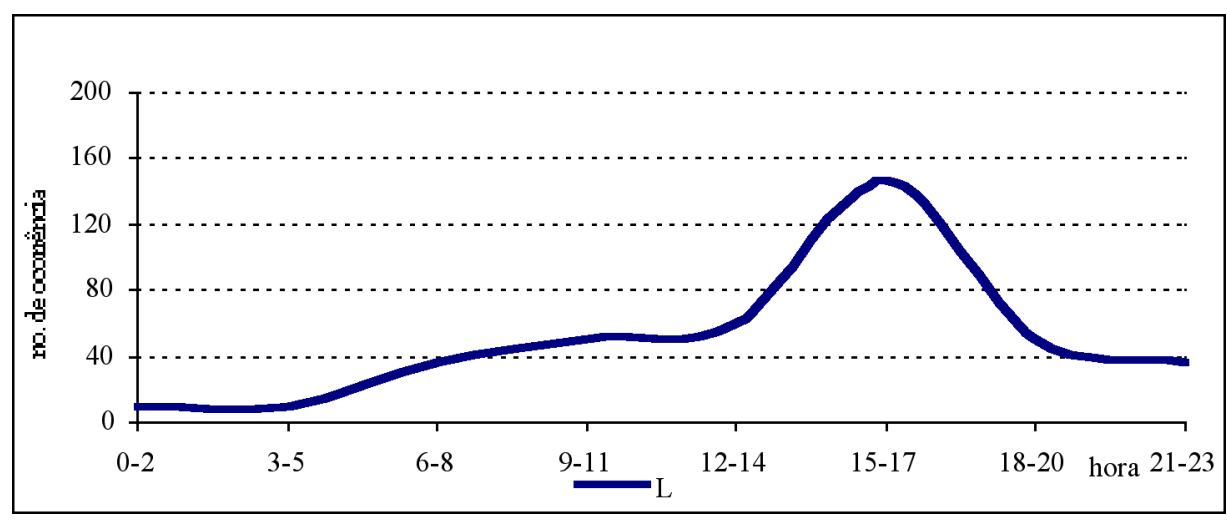

Nota: $(\mathrm{L}=$ lambendo $)$ 
$(2,22 \pm 0,24)$ seja uma atividade que antecipa o período de repouso, uma vez que esta atividade precede o último, conforme registrado neste estudo (Fig.4).

\section{Conclusão}

Apesar de serem animais domésticos, as vacas leiteiras herdaram de seus ancestrais remotos algumas características comportamentais que são vitais para a sua sobrevivência. A manutenção de um indivíduo implica em atividades comportamentais que minimizem a taxa de deterioração do organismo, mantendo o em estado ótimo para suportar situações de oposição ou perigo. Estas atividades, com base genética, asseguram a perpetuação da espécie. Os comportamentos alimentares, movimentação, limpeza, repouso e eliminação constituem algumas das atividades de manutenção dos bovinos.
Desta forma, um melhor conhecimento das atividades comportamentais dos bovinos possibilita adaptar e melhorar o seu desempenho produtivo, uma vez que as necessidades fisiológicas têm efeitos imediatos sobre o custo do manejo, enquanto que as necessidades comportamentais tendem a ser crônicas, tendo impacto sobre a saúde e bem-estar animal, que são o ponto fundamental no valor da produção animal.

\section{Referências}

HANCOCK, J. Grazing habits of dairy cows in New Zealand. Empire J. Experimental. Agric., v. 18, p. 249-263, 1950.

Uniformity trials: grazing behavior. In: Studies in Monozygotica Cattle Twins. New Zealand Department of Agriculture Research Division Publication: Hamilton, n. 63, p. 85-122. 1954. 